\title{
EFFECTS OF THE DOR PROCEDURE ON LEFT VENTRICULAR DIMENSION AND SHAPE AND GEOMETRIC CORRELATES OF MITRAL REGURGITATION ONE YEAR AFTER SURGERY
}

\author{
Marisa Di Donato, $\mathrm{MD}^{\mathrm{a}}$ \\ Michel Sabatier, $\mathrm{MD}^{\mathrm{b}}$ \\ Vincent Dor, $\mathrm{MD}^{\mathrm{b}}$ \\ Gian Franco Gensini, MD \\ Anna Toso, $\mathrm{MD}^{\mathrm{a}}$ \\ Mauro Maioli, MD \\ Alfred W. H. Stanley, MD \\ Constantine Athanasuleas, $\mathrm{MD}^{\mathrm{c}}$ \\ Gerald Buckberg, MD ${ }^{\mathrm{d}}$
}

Objectives: In the present study we retrospectively analyzed ventriculographic data from symptomatic patients after myocardial infarction who underwent the Dor procedure (endoventricular circular patch plasty repair) to evaluate left ventricular shape 1 year after the operation and to analyze the geometric correlates of late mitral regurgitation.

Methods: Forty-four patients with previous transmural anterior myocardial infarction comprised the study group. Left ventricular volumes, global left ventricular systolic and diastolic sphericity, the extent of wall motion abnormalities, and the presence and degree of mitral regurgitation were analyzed before and 1 year after operation.

Results: Comparing preoperative diastole to systole within the cardiac cycle, left ventricular shape becomes more elliptical in systole than it was in diastole (eccentricity index closer to 1). The intervention leads to an increased diastolic sphericity, but for each cardiac cycle, the systolic shape is more elliptical relative to its diastolic counterpart in respect to basal conditions. Mitral regurgitation was detected after operations in 17 patients; 14 of them did not have mitral regurgitation before operations. Patients with late mitral regurgitation had greater preoperative volumes and more spherical chamber than did patients without late mitral regurgitation.

Conclusions: Despite a more spherical postoperative left ventricular chamber, systolic pump function improves after the Dor procedure, mainly for the improvement in inferior wall shortening. The presence of late mitral regurgitation is relatively frequent in this series of patients, and this emphasizes the importance of a more accurate quantitative evaluation of preoperative functional mitral regurgitation to repair the valve when appropriate. Geometric correlates of late mitral regurgitation appeared to be greater chamber sphericity and larger ventricular volumes preoperatively. ( $\mathrm{J}$ Thorac Cardiovasc Surg 2001;121:91-6)
From the Department of Internal Medicine and Cardiology, ${ }^{\text {a }}$ University of Florence, Italy, the Centre Cardiothoracique de Monaco, ${ }^{\mathrm{b}}$ Monaco, the Kemp Carraway Heart Institute, ${ }^{\mathrm{c}}$ Birmingham, Ala, and the Department of Cardiothoracic Surgery, ${ }^{\mathrm{d}}$ UCLA, Los Angeles, Calif.

The study was carried out with the active contribution of the RESTORE group.

Received for publication April 10, 2000; revisions requested July 10, 2000; revisions received Aug 2, 2000; accepted for publication Sept 6, 2000 .

Address for reprints: Marisa Di Donato, MD, Via dei Fossi 12, 50123 Firenze, Italy.

Copyright (C) 2001 by The American Association for Thoracic Surgery

0022-5223/2001 $\$ 35.00+0 \quad \mathbf{1 2 / 1 / 1 1 1 3 7 9}$

doi: $10.1067 / \mathrm{mtc} .2001 .111379$
The Dor procedure (endoventricular circular patch
plasty repair of the left ventricle with associated
coronary grafting) is a relatively new surgical technique
that applies to patients with ventricular dysfunction
after an infarction for either akinesia or dyskinesia. ${ }^{1-6}$ It
consists of reducing and reconstructing the left ventric-
ular (LV) chamber by using an endoventricular circular
patch and grafting diseased coronary vessels.
Postinfarction left ventricles are characterized by
changes in shape and function (remodeling) frequently
complicated by functional mitral regurgitation (MR),
leading to cardiac dysfunction and clinical heart failure,
which heavily affect survival. ${ }^{7-11}$ We have previously 
Table I. Hemodynamic data in the study group $(n=44)$

\begin{tabular}{lccc}
\hline & Baseline & Early postoperative period & Late postoperative period \\
\hline EDVI $\left(\mathrm{mL} / \mathrm{m}^{2}\right)$ & $201 \pm 78$ & $127 \pm 46^{*}$ & $140 \pm 47^{*}$ \\
$\mathrm{ESVI}\left(\mathrm{mL} / \mathrm{m}^{2}\right)$ & $137 \pm 70$ & $67 \pm 37^{*}$ & $77 \pm 33^{*}$ \\
$\mathrm{EF}(\%)$ & $34 \pm 13$ & $50 \pm 12^{*}$ & $46 \pm 10^{*}$ \\
Mean PAP $(\mathrm{mm} \mathrm{Hg})$ & $21 \pm 10$ & $17 \pm 7^{*}$ & $26 \pm 14^{*} \dagger$ \\
$\mathrm{CWP}(\mathrm{mm} \mathrm{Hg})$ & $16 \pm 10$ & $12 \pm 6^{*}$ & $17 \pm 10 \dagger$ \\
$\mathrm{SVI}\left(\mathrm{mL} \cdot \mathrm{beat}^{-1} \cdot \mathrm{m}^{-2}\right)$ & $64 \pm 25$ & $59 \pm 22$ & $63 \pm 22$ \\
$\mathrm{CI}\left(\mathrm{L} \cdot \mathrm{min}^{-1} \cdot \mathrm{m}^{-2}\right)$ & $2.6 \pm 0.6$ & $2.7 \pm 0.6$ & $2.7 \pm 0.5$ \\
Long axis length $(\mathrm{cm})$ & $12.4 \pm 1.6$ & - & $9.8 \pm 1^{*}$ \\
Short axis length $(\mathrm{cm})$ & $8.5 \pm 1.3$ & - & $8.7 \pm 1.1$ \\
A $\%$ & $53 \pm 14$ & - & $28 \pm 16^{*}$ \\
\hline
\end{tabular}

$E S V I$, End-systolic volume index; PAP, pulmonary artery pressure; $C W P$, capillary wedge pressure; $S V I$, stroke volume index; $C I$, cardiac index; $A \%$, extent of asynergy.

$* P<.0001$ versus baseline.

$\dagger P<.0001$ versus the early postoperative period.

Table II. Changes in EI in the study group $(n=44)$

\begin{tabular}{lcc}
\hline & Baseline & $1 y$ \\
\hline Diastolic EI & $0.7 \pm 0.09$ & $0.44 \pm 0.18^{*}$ \\
Systolic EI & $0.79 \pm 0.07$ & $0.66 \pm 0.1^{*}$ \\
Systolic/diastolic changes in EI & $0.09 \pm 0.05$ & $0.22 \pm 0.17^{*}$ \\
Long axis \% shortening & $2.8 \pm 3.4$ & $8.3 \pm 4.1^{*}$ \\
Short axis \% shortening & $18.3 \pm 12$ & $24 \pm 8.6^{*}$ \\
\hline
\end{tabular}

$* P<.0001$ versus basal level.

extensively studied the effects of the Dor procedure in a large series of patients, and we have demonstrated that the procedure improves pump function, clinical status, and survival, even in patients with severe cardiac dysfunction. ${ }^{1-6}$ In addition, we have quantitatively analyzed early changes in cardiac shape in patients submitted to the Dor procedure, ${ }^{12}$ but we have never investigated late LV shape changes and how they relate to late MR, which is not an unusual finding in our overall population. We therefore analyzed ventriculographic data from symptomatic patients after a myocardial infarction (MI) who underwent the Dor procedure through almost 1 year of activity (June 1997-August 1998) to determine late LV shape changes induced by the operation and to analyze geometric correlates of late MR.

\section{Methods}

Between June 1997 and August 1998, 70 patients were submitted to the Dor procedure at the Cardiothoracique Center of Monaco. The perioperative mortality rate for the entire group was $4.2 \%$ (3/70). Of the 67 surviving patients, 44 patients (40 men and 4 women with a mean age of $58 \pm 6$ years) had hemodynamic control 1 year after their operations and repre- sent the study group. For the 23 patients who have not been studied 1 year after their operations (either because they refused to repeat the study or because they were referred from other countries), follow-up information was obtained during patient visits or by means of telephone interview. All patients had an anterior transmural MI and were submitted to the Dor procedure and associated coronary grafting for symptoms related to congestive heart failure or angina.

Right and left heart catheterization was performed preoperatively and before discharge in all patients and 1 year after operation in the study group. Cardiac output was measured in triplicate with the thermodilution method. LV silhouettes from right anterior oblique $30^{\circ} \mathrm{LV}$ angiography were manually traced by an experienced angiographer, and volumes were calculated with the monoplane method of Chapman and colleagues. ${ }^{13}$ Ejection fraction (EF) was derived, and residual contractile EF was also calculated by applying the singleplane method described by Kapelanski and colleagues. ${ }^{14}$ Regional wall motion was assessed by the Centerline method, ${ }^{15}$ and the extent of asynergy was calculated as the ratio between the extent of asynergy greater than 2 SDs from normal mean values and the perimeter of the LV. The presence and extent of angiographic MR were graded on a standard scale (0-4).

Preoperative and postoperative global LV shape was assessed by calculating the eccentricity index (EI) in diastole and systole in all patients by using the following formula:

$$
\sqrt{\mathrm{L}^{2}-\mathrm{D}^{2}} / \mathrm{L}
$$

where $\mathrm{L}$ is defined as the major axis, and $\mathrm{D}$ is defined as the minor axis. ${ }^{16}$ This index takes into account the long and minor axis and ranges from 1 (ellipse) to 0 (circle). The systolic-diastolic change of EI for each cardiac cycle and the percentage shortening of the long and minor axis were also calculated.

Results are expressed as the mean \pm SD. Differences among patients were tested by using analysis of variance. The paired $t$ test was used to compare preoperative and postoperative data. 


\section{Results}

Table I reports hemodynamic data in the study group (mean $\pm \mathrm{SD}$ ). A significant reduction in $\mathrm{LV}$ volumes and an increase in EF are observed early after the operation and are maintained at significant levels 1 year after. The extent of asynergy is significantly reduced. The long axis is shortened by the operation (from 12.4 \pm 1.6 to $9.8 \pm 1.0 \mathrm{~cm}$ in diastole), and the short axis is not shortened by the operation (from $8.5 \pm 1.3$ to $8.7 \pm$ $1.1 \mathrm{~cm}$ in diastole).

Table II shows the EI in diastole and in systole and its systolic-diastolic change, as well as the percentage shortening of the long and minor axis. Within the cardiac cycle, LV shape becomes more elliptical in systole than it was in diastole (EI closer to 1). The intervention significantly reduces EI, but systolic-diastolic change is significantly augmented by the operation (from 0.09 to 0.22 ), despite the $\mathrm{LV}$ chamber being made more spherical (EI closer to 0). The percentage shortening of long and minor axis is significantly increased by the intervention.

Regional wall motion, as assessed by the centerline method, improves after the operation at the posterobasal, inferior, and anterobasal zones, thus confirming our previous results (Fig 1). ${ }^{1,17}$

MR was detected preoperatively in 5 of the 44 patients. The valve was repaired at the time of the operation in 4 patients with moderate-to-severe MR (grade 2-3) by using the standard mitral reconstruction or posterior annuloplasty alone if it was a pure annulus dilatation. One patient had grade $1 \mathrm{MR}$, and the valve was not repaired. One year after the operation, 17 of 44 patients had MR; 14 of them did not have MR before the operation (Table III). Left ventriculography demonstrated that patients with late MR had greater end-diastolic and end-systolic volumes than did patients without MR, both preoperatively and postoperatively. Late changes in patients with MR are characterized by an increase in short axis length (from $8 \pm 1$ to $10 \pm 3 \mathrm{~mm}$ ), a significant increase in mean pulmonary artery pressure (from $23 \pm 8$ to $34 \pm 16 \mathrm{~mm} \mathrm{Hg}, P<.001$ ), and an increase in capillary wedge pressure (from $16 \pm 6$ to 23 $\pm 12 \mathrm{~mm} \mathrm{Hg}, P<.05)$. Patients with late MR had a more spherical diastolic chamber before the operation and a more spherical shape both in diastole and in systole after their operations. Quantitative wall motion analysis demonstrated that there were no significant differences in the extent of asynergy, but patients with MR had a longer, although not significant, delay from MI (50 \pm 54 vs $28 \pm 40$ months; Table IV).

Preoperative MR was present in 4 of the 23 patients without late angiographic control and was repaired in 1 patient with grade $2 \mathrm{MR}$.

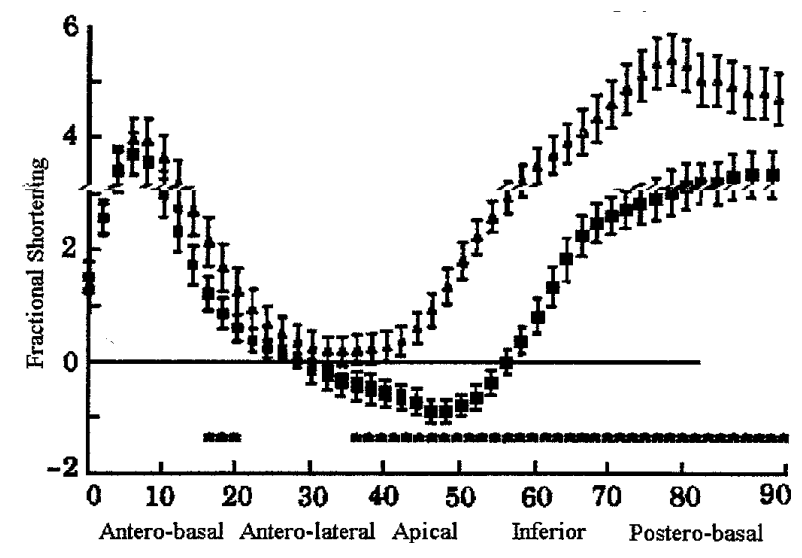

Fig 1. Mean regional wall motion analysis before and after operation. Vertical bars indicate the standard error; small stars indicate significant differences.

Follow-up data for the entire group are given in Table V.

\section{Discussion}

The present study confirms improved LV systolic function after the Dor procedure, as assessed by the increase in global EF, because of the decrease in enddiastolic volume index (EDVI), with little change in stroke volume index and the improvement in regional fractional shortening. Theoretically, an LV mass reduction should depress pump function, ${ }^{18}$ but this is not the case in our patients because in terms of the FrankStarling relationship relating stroke volume or cardiac index to EDVI, our results indicate a leftward shift of the curve but not a downward shift, thus reflecting an overall pump function improvement. This improvement occurred despite the more spherical postoperative ventricular shape. The operation shortens the long axis but leaves the short axis length unchanged, thereby increasing ventricular diastolic sphericity. Conventional wisdom would expect a more spherical shape to adversely affect systolic function, but it did not. Long axis shortening is improved by the operation (from $2.8 \% \pm 3.4 \%$ to $8.3 \% \pm 4.1 \%$ ), as is short axis shortening (from $18.3 \% \pm 12 \%$ to $24 \% \pm 8.6 \%$ ), but as in physiologic conditions, the contribution to ejection is much greater at the short axis. This asymmetry produced a more elliptical systolic shape relative to its diastolic counterpart postoperatively, and for each cardiac cycle, the systolic eccentricity was greater than the diastolic eccentricity, reflecting increased short axis contraction. The operation significantly reduced the diastolic volumes in the previously very dilated left ventricles. Two possible mechanisms could explain the 
Table III. Presence and degree of MR

\begin{tabular}{|c|c|c|c|c|c|c|}
\hline & \multicolumn{3}{|c|}{ Patients with late $M R(n=17)$} & \multicolumn{3}{|c|}{ Patients without late $M R(n=27)$} \\
\hline & Baseline & $\begin{array}{c}\text { Early postoperative } \\
\text { period }\end{array}$ & $\begin{array}{c}\text { Late postoperative } \\
\text { period }\end{array}$ & Baseline & $\begin{array}{c}\text { Early postoperative } \\
\text { period }\end{array}$ & $\begin{array}{c}\text { Late postoperative } \\
\text { period }\end{array}$ \\
\hline MR (n) & 3 & 1 & 17 & 2 & 2 & 0 \\
\hline Grade I & 1 & - & 9 & - & 1 & - \\
\hline Grade II & 1 & 1 & 4 & 2 & 1 & - \\
\hline Grade III & 1 & - & 4 & - & - & - \\
\hline
\end{tabular}

Table IV. Characteristics of patients with and without late MR

\begin{tabular}{|c|c|c|c|c|c|c|}
\hline & \multicolumn{3}{|c|}{ Patients with $M R^{*}(n=17)$} & \multicolumn{3}{|c|}{ Patients without $M R+(n=27)$} \\
\hline & \multicolumn{3}{|c|}{ Early postoperative } & \multicolumn{3}{|c|}{ Early postoperative } \\
\hline & Baseline & period & $1 y$ & Baseline & period & $1 y$ \\
\hline $\operatorname{EDVI}\left(\mathrm{mL} / \mathrm{m}^{2}\right)$ & $232 \pm 77$ & $132 \pm 47 \ddagger$ & $172 \pm 46 \$ 8$ & $183 \pm 74$ & $115 \pm 61$ \% & $122 \pm 37 \ddagger$ \\
\hline $\operatorname{ESVI}\left(\mathrm{mL} / \mathrm{m}^{2}\right)$ & $160 \pm 78$ & $72 \pm 30$ \& & $96 \pm 36 \neq \S \|$ & $124 \pm 63$ & $59 \pm 43 \ddagger$ & $65 \pm 24 \ddagger$ \\
\hline $\mathrm{EF}(\%)$ & $34 \pm 13$ & $46 \pm 11 \ddagger$ & $44 \pm 11 \ddagger$ & $33 \pm 13$ & $51 \pm 11 \ddagger$ & $47 \pm 9 \ddagger$ \\
\hline $\mathrm{EFc}(\%)$ & $48 \pm 12$ & & & $43 \pm 10$ & & \\
\hline $\operatorname{SVI}\left(\mathrm{mL} \cdot\right.$ beat $\left.^{-1} \cdot \mathrm{m}^{-2}\right)$ & $72 \pm 19$ & $63 \pm 27$ & $75 \pm 23$ & $59 \pm 27$ & $57 \pm 19$ & $57 \pm 19$ \\
\hline $\mathrm{CI}\left(\mathrm{L} \cdot \mathrm{min}^{-1} \cdot \mathrm{m}^{-2}\right)$ & $2.6 \pm 0.7$ & $2.6 \pm 0.6$ & $2.6 \pm 0.5$ & $2.7 \pm 0.6$ & $2.6 \pm 0.6$ & $2.8 \pm 0.5$ \\
\hline EI diastole & $0.67 \pm 0.1 \|$ & & $0.38 \pm 0.2 \ddagger$ & $0.72 \pm 0.08$ & & $0.48 \pm 0.17 \ddagger$ \\
\hline EI systole & $0.78 \pm 0.06$ & & $0.62 \pm 0.09+$ & $0.80 \pm 0.17$ & & $0.69 \pm 0.1 \ddagger$ \\
\hline S/D changes in EI & $0.11 \pm 0.05$ & & $0.24 \pm 0.22 \ddagger$ & $0.07 \pm 0.05$ & & $0.21 \pm 0.10 \ddagger$ \\
\hline PAP (mm Hg) & $23 \pm 8$ & $18 \pm 8 \ddagger$ & $34 \pm 16 \neq \S$ & $20 \pm 11$ & $16 \pm 4 \ddagger$ & $21 \pm 11 \S$ \\
\hline CWP (mm Hg) & $16 \pm 6$ & $11 \pm 6 \ddagger$ & $23 \pm 12 \ddagger \S \|$ & $13 \pm 6$ & $10 \pm 4 \ddagger$ & $14 \pm 8 \S$ \\
\hline $\mathrm{A} \%$ & $51 \pm 12$ & & $22 \pm 16 *$ & $55 \pm 14$ & & $34 \pm 15 \ddagger$ \\
\hline
\end{tabular}

$E S V I$, End-systolic volume index; $E F c$, contractile ejection fraction; $S V I$, stroke volume index; $C I$, cardiac index; $S / D$, systolic-diastolic; $P A P$, pulmonary artery pressure; $C W P$, capillary wedge pressure; $A \%$, extent of asynergy.

$*$ Patients with MR have a mean \pm SD age of $58 \pm 9$ years and delay from MI of $50 \pm 54$ months.

$\dagger$ Patients without MR have a mean \pm SD age of $57 \pm 8$ years and delay from MI of $28 \pm 40$ months.

$\ddagger P<.001$ versus baseline.

$\S P<.05$ versus early postoperative period.

$\| P<.001$ between groups.

improvement in short axis contractile properties. First, preoperatively, the remote short axis myocardium may have been working behind its preload reserve because the large ventricular volumes and high wall tension would adversely affect shortening. Postoperatively, the reduced volume would change the geometric relationship between wall thickness and volume, thereby reducing wall stress and allowing the short axis myocardium to contract more vigorously despite a more spherical ventricular shape. Second, the reduced postoperative volume may have altered the cleavage plane angle and fiber orientation so as to allow for a more efficient shortening.

The presence of late MR deserves some comments: in the overall series of our patients who had hemodynamic study 1 year after the operation (from 1987-1999), the incidence of late MR was 27\%; the degree of MR was mild in $81 \%$ of the patients. In the present series the inci- dence of late MR was 38\% (17/44 patients), and it developed also in patients who did not have detectable MR at angiography before the operation. It is known that MR is functional more often than organic in patients with severe LV dysfunction, and it is more difficult to detect clinically. Furthermore, angiography is not sensitive to $\mathrm{MR}$, and it could be missed at ventriculography (especially in very dilated ventricles) or the degree might have been underestimated. All patients had an early angiographic study after the operation, but MR was detected only in 3 patients (Table III). It is true that at early angiographic control, loading conditions are different from those the patients have 1 year after their operations (see lower pressures). From the present data, MR seems to occur late after the operation in the great majority of patients. The degree of postoperative MR was mild in 9 patients (two previously repaired) and moderate to severe in 8 patients. 
Table V. Clinical events and mortality at follow-up in the overall group

\begin{tabular}{lccc}
\hline & $\begin{array}{c}\text { Patients with late MR } \\
(n=17)\end{array}$ & $\begin{array}{c}\text { Patients without late MR } \\
(n=27)\end{array}$ & $\begin{array}{c}\text { Patients without angiographic control } \\
(n=23)\end{array}$ \\
\hline Death & 2 & 0 & 3 \\
NYHA III-IV & 2 & 1 & 2 \\
Angina & 1 & 3 & 1 \\
CHF & 2 & 2 & 2 \\
SV arrhythmia & 2 & - & -
\end{tabular}

NYHA, New York Heart Association class; $C H F$, congestive heart failure; $S V$, supraventricular.

Our findings should encourage a more accurate evaluation of the presence and the degree of functional MR with Doppler quantitation before the operation, before or during operative transesophageal echocardiography (TEE), or both. The use of intraoperative TEE has been recently introduced in all patients with very dilated ventricles in our center, and the results will be made available in the future. On average, patients with late MR in our series had preoperative larger and more spherical ventricles than did patients without MR and a longer, although not significant, delay from MI in respect to patients without MR but not a greater extent of asynergy, as quantitatively evaluated. The association of MR with increased sphericity in patients after infarction has been known since the early 1970s..$^{19,20}$ One year after the operation, patients with MR showed a significant increase in EDVI in respect to early control (Table IV); volumes were significantly larger, and the chamber was significantly more spherical in respect to patients without late MR (late remodeling). The mechanism underlying late MR is complex, and MR per se could be a cause, as well as a consequence, of redilation. However, at least in patients with mild MR (degree 1), it is unlikely that the late increase in volumes is due to the valvular volume overload. It can most likely be the expression of a late further remodeling in ventricles with severe tissue damage and profound structural extracellular collagen matrix alterations. ${ }^{21,22}$ Chamber enlargement alone is not sufficient to account for MR, but a distortion of shape leading to an alteration in the angle at which chordal structures are tethered to the mitral leaflets might be an important component. ${ }^{23,24}$ In fact, in patients with late MR, we found a postoperative and more spherical chamber that could have led to a different distribution of intraventricular forces.

In the present series we did not quantitatively calculate LV curvature, but another explanation for a dysfunctioning mitral apparatus could be an outward curvature at the inferior and posterobasal regions, as we observed in some few patients after the Dor operation in a previous study. ${ }^{12}$
Surgeons should be aware of the importance of detecting and quantitating functional MR before the operation. In our opinion a TEE study should be performed before the operation or intraoperatively, and a surgical procedure tailored on the type of lesion should be associated to the procedure (posterior annuloplasty or mitral reconstruction or replacement). Determining whether mitral repair should be performed, even in the absence of MR, at the time of examination would require a larger experience. Because in our patients the incidence of late MR is relatively high and is frequently associated with pulmonary hypertension, ${ }^{25}$ we think that mitral valve repair would be advisable at least in patients with very dilated ventricles.

In conclusion, late changes in LV shape after the Dor procedure lead to an increased diastolic sphericity because the intervention shortens the long axis but leaves the short axis unchanged. However, for each cardiac cycle, the systolic shape is more elliptical relative to its diastolic counterpart because of the prevalent contribution of the short axis to the ejection most likely linked to the improved geometric relationship between wall thickness and volume induced by this type of surgical procedure.

The late presence of MR and the development of late pulmonary hypertension appeared to be related to a preoperatively more severe remodeling. This, as already pointed out in our previous articles, indicates that postinfarction $L V$ reconstruction, as with any other reparative operation, should be performed earlier to better recover LV function, shape, and geometry.

\section{REFERENCES}

1. Di Donato M, Barletta G, Maioli M, et al. Early hemodynamic results of left ventricular reconstructive surgery for anterior wall left ventricular aneurysm. Am J Cardiol 1992;69:886-90.

2. Di Donato M, Sabatier M, Montiglio F, et al. Outcome of left ventricular aneurysmectomy with patch repair in patients with severely depressed pump function. Am J Cardiol 1995;76:55761.

3. Dor V, Sabatier M, Di Donato M, et al. Efficacy of endoventricular patch plasty in large postinfarction akinetic scar and severe 
left ventricular dysfunction: comparison with a series of large dyskinetic scar. J Thorac Cardiovasc Surg 1998;116:50-9.

4. Dor V, Sabatier M, Montiglio F, Rossi P, Toso A, Di Donato M. Results of nonguided subtotal endocardiectomy associated with left ventricular reconstruction in patients with ischemic ventricular arrhythmias. J Thorac Cardiovasc Surg 1994;107:1301-8.

5. Dor V. Surgery for left ventricular aneurysm. Curr Opin Cardiol 1990;5:773-80.

6. Di Donato M, Sabatier M, Dor V, Toso A, Maioli M, Fantini F. Akinetic versus dyskinetic postinfarction scar: relation to surgical outcome in patients undergoing endoventricular circular patch plasty repair. J Am Coll Cardiol 1997;29:1569-75.

7. Pfeffer MA, Braunwald E. Ventricular remodeling after myocardial infarction. Experimental observations and clinical implications. Circulation 1990;81:1161-72.

8. Lamas GA, Pfeffer MA. Left ventricular remodeling after acute myocardial infarction: clinical course and beneficial effects of angiotensin-converting enzyme inhibition. Prog Cardiol 1991;121:1194-202.

9. McKee PA, Castelli WP, McNamara PM, Kannel WB. The natural history of congestive heart failure: the Framingham study. N Engl J Med 1971;285:1441-6.

10. Cohn JN, Archibald DG, Ziesche S, et al. Effect of vasodilator therapy on mortality in chronic congestive heart failure. Results of a Veterans Administration Cooperative study. N Engl J Med $1986 ; 314: 1547-52$

11. The Consensus Trial Study Group. Effects of Enalapril on mortality in severe congestive heart failure. Results of the Cooperative North Scandinavian Enalapril Survival Study. N Engl J Med 1987;316:1429-35.

12. Dor V, Montiglio F, Coste P, et al. Left ventricular shape changes induced by aneurysmectomy with endoventricular circular patch plasty reconstruction. Eur Heart J 1994;15:1063-9.

13. Chapman CB, Baker O, Reynolds J, Bonte FJ. Use of biplane cinefluorography for measurement of ventricular volume. Circulation 1958;18:1105-17.

14. Kapelanski DP, Al-Sadir J, Lamberti JJ, Anagnostopoulos CE.
Ventriculographic features predictive of surgical outcome for left ventricular aneurysm. Circulation 1978;58:1167-74.

15. Sheehan FH, Bolson EL, Dodge HT, Mathey DG, Shofer J, Woo HW. Advantages and applications of the centerline method for characterizing regional ventricular function. Circulation 1986;74:293-305.

16. Fischl SJ, Gorlin R, Herman MV. Cardiac shape and function in aortic valve disease. Physiologic and clinical implications. Am J Cardiol 1977;39:170-6.

17. Di Donato M, Sabatier M, Toso A, et al. Regional myocardial performance of non-ischemic zones remote from anterior wall left ventricular aneurysm. Effects of aneurysmectomy. Eur Heart J 1995;16:1285-92.

18. Dickstein ML, Spotniz HM, Rose EA, Burkhoff D. Heart reduction surgery: an analysis of the impact on cardiac function. $J$ Thorac Cardiovasc Surg 1997;113:1032-40

19. Perloff JK, Roberts WC. The mitral apparatus. Circulation 1972;46:227-39

20. Gibson DG, Brown DJ. Continuous assessment of left ventricular shape in man. Br Heart J 1975;37:904-10.

21. Zhao M, Zhang H, Robinson TF, Factor SM, Sonnenblick EH. Profound structural alterations of the extracellular collagen matrix in postischemic dysfunctional stunned but viable myocardium. J Am Coll Cardiol 1987;10:1322-34.

22. Anversa P, Olivetti G, Capasso JM. Cellular basis of ventricular remodeling after myocardial infarction. Am J Cardiol 1991;68:7D-16D.

23. Vokonas PS, Gorlin R, Chon PF, Herman MV, Sonnenblick EH. Dynamic geometry of the left ventricle in mitral regurgitation. Circulation 1973;48:786-95.

24. Lamas GA, Mitchell GF, Flaker GC, et al. Clinical significance of mitral regurgitation after acute myocardial infarction. Circulation 1997;96:827-33.

25. Maioli M, Di Donato M, Sabatier A, Toso G, Barletta F, Fantini $\mathrm{V}$, et al. Right hemodynamics in postinfarction left ventricular aneurysm: effects of aneurysm patch repair after 1 year. Coronary artery disease—-from prevention to intervention. 1998;129:513A.

\section{Timely}

The Journal of Thoracic and Cardiovascular Surgery delivers the information you need now. Articles usually appear within four months of acceptance. 